Article

\title{
Cross-Scale and Cross-Level Dynamics: Governance and Capacity for Resilience in a Social-Ecological System in Taiwan
}

\author{
Hsing-Sheng Tai \\ Department of Natural Resources and Environmental Studies, National Dong Hwa University, \\ No.1, Sec.2, Da Hsueh Rd., Shoufeng, Hualien 97401, Taiwan; E-Mail: hstai@mail.ndhu.edu.tw; \\ Tel.: +886-3-8633342; Fax: +886-3-8633320
}

Academic Editor: Yu-Pin Lin

Received: 24 December 2014 / Accepted: 9 February 2015 / Published: 13 February 2015

\begin{abstract}
Resilience thinking has strongly influenced how people understand and pursue sustainability of linked social-ecological systems. Resilience thinking highlights the need to build capacity and manage general system properties in a complex, constantly changing world. I modified an analytical framework to address associations among cross-scale and cross-level dynamics, attributes of governance, and capacity to enhance resilience. The Danungdafu Forestation Area represents one of Taiwan's most controvisal cases concerning land use, indigenous rights, and environmental issues. Analysis of this Taiwanese experience from a social-ecological perspective can show how current capacities for managing resilience are related to critical governance attributes. Analysis helped identify fundamental flaws in current governance and key issues needing to be addressed. The Danungdafu Forestation Area should transition towards a governance regime that is more participatory, deliberative, multi-layered, accountable, just, and networked. This can be done by developing an intermediate level institution that coordinates the cross-scale and cross-level interactions that better fit this social-ecological system.
\end{abstract}

Keywords: social-ecological system; governance; resilience stewardship; sustainability

\section{Introduction}

Since the Brundtland Report [1], sustainable development and sustainability have been promoted worldwide as guiding principles for Earth's future. Numerous indicators, models, actions and institutions have been developed to make these concepts operational for the pursuit of sustainability goals. Although these efforts certainly constitute important starting points, questions are still raised 
concerning their fundamental limitations. Anderies et al. [2] argue "it is insufficient, and even dangerous, to assume that individual actions will aggregate up to generate system-level sustainability." The complex and uncertain nature of feedback systems demonstrates a need to understand the cross-scale and cross-level dynamics of the system as a whole. Otherwise, individual actions, however well-intentioned, are eventually futile.

Resilience thinking represents an academic paradigm shift that can help clarify the meaning of sustainability [3]. Resilience addresses the dynamics of complex social-ecological systems from a systems perspective [4-6]. By recognizing characteristics of complexity, uncertainty, nonlinearity, thresholds, irreversibility, and multi-scale and multi-level interactions in a changing world, resilience thinking goes beyond traditional resource management to embrace the dynamic and complex nature of social-ecological systems [7].

Rather than focusing on narrowly defined policy goals and seeking optimal states, resilience thinking stresses that human societies should manage general system properties with resilience, adaptability, and transformability in mind [4-6]. Resilience represents the capacity of a social-ecological system, when facing a new context, to continually adapt, maintain fundamental functions and structures, and remain within critical thresholds. Resilience, adaptability and transformability possess the nature of both conservation and creation. They operate and interact across multiple scales, giving insight into sustainability. Adaptability represents the capacity of social-ecological systems to adapt and to follow the current development trajectories while maintaining original system properties. Transformability is the capacity to cross thresholds into new development trajectories and new system properties when existing conditions are untenable. Human societies should foster the resilience, adaptability, and transformability properties of social-ecological systems to enhance Earth's system resilience $[4,6]$.

To clarify confusion regarding sustainability and resilience, Anderies et al. [2] said sustainability "should be used to refer to an analytical framework to guide actions across all levels of organizations related to the way human societies operate and interact with their environments." This analytical framework includes two main components: sustainability measures of system performance and sustainability decision-making context. It is in the decision-making context, Anderies et al. [2] argued, that resilience thinking becomes critical and useful for adequately understanding processes associated with pursuing sustainability goals. Knowledge about the dynamics of social-ecological systems is central for developing governance structures that effectively contribute to achieving sustainability goals.

By applying a resilience-based analytical framework, this article focuses on governance issues by examining associations among cross-scale and cross-level dynamics, governance, and capacity to enhance resilience of a regional social-ecological system. Specifically, it addresses the following pivotal question: how do processes and patterns of cross-scale and cross-level interactions influence attributes of a governance system and strengthen or weaken its capacity for resilience? Therefore, I investigated the long-term dynamics of a social-ecological system: The Danungdafu Forestation Area (DFA) in Hualien, Taiwan. The DFA represents one of Taiwan's most controversal cases of land use, indigenous rights, and environmental issues [8].

This paper is organized into six sections. Section 2 reviews existing analytical frameworks on governance, cross-scale dynamics, and capacity for managing resilience. In this section, I recommend amendments to the existing framework. Section 3 describes the research approach. Section 4 presents 
historical, political, social, economic, and ecological settings from which the DFA case evolved. This section also examines the cross-scale and cross-level dynamics of DFA. In Section 5, I analyze governance system attributes and capacity for managing resilience, based on the modified framework in Section 2. In Section 6, I present the main conclusions and policy implications.

\section{Governance, Cross-Scale and Cross-Level Dynamics, and Capacity}

Governance is a central issue of sustainability [9]. Any discussion of resilience must examine the capacity of governance to adapt to changing conditions [5]. Governance refers to the structures and processes through which human societies share power; shape incentives, behaviors, identity, and decision-making; interact with each other; and influence outcomes. Governance involves: (1) stakeholders and actors, including government, communities, businesses, and non-governmental organizations; (2) different institutions, both formal and informal; and (3) various actions and decision-making processes, including governmental and jurisdictional processes, debates, negotiation, mediation, public consultations, conflict resolution, elections, and protests [9-11].

In complex, multi-scale and multi-level circumstances, cross-scale and cross-level dynamics are recognized as core issues for governance of social-ecological systems [12-15]. Gibson et al. [16] (p. 218) define scale as "the spatial, temporal, quantitative, or analytical dimensions used to measure and study any phenomenon". They define levels as "units of analysis that are located at the same position on a scale". A number of scholars [12-15,17,18] have urged the need for scale- and level-sensitive governance approaches, calling for more in-depth understanding of the complex processes associated with scale issues. Cash et al. [12] concluded that people consciously dealing with scale issues are generally more able to successfully identify problems and seek sustainable solutions. Armitage [15] argued that, in a multi-level world, multi-level governance can contribute to adaptation capacity which is central to resilience. Young [14] focused on differentiating governance regimes among levels on the jurisdictional scale, identifying commonly interacting patterns, including dominance, separation, merger, negotiated agreement, and system change. He stressed that these interacting patterns often profoundly influence outcomes of governance in terms of sustainability.

Through a comprehensive review, Termeer et al. [17] compared three representative governance regimes from the perspective of scale: monocentric governance, multilevel governance, and adaptive governance. Monocentric governance exists when central state authorities are in charge of governing social-ecological systems. It mainly addresses jurisdictional scale issues. Multilevel governance extends its focus to multiple level interactions, specifically at jurisdictional and spatial scales. In this model, governance tasks allocated to different levels, whether involving public or private actors, need to coordinate with each other. Adaptive governance considers a whole spectrum of cross-level and cross-scale interactions. These interactions may involve jurisdictional and spatial scales, as well as temporal, institutional, management, network, and knowledge scales.

In the associations between governance and the capacity to manage resilience, capacity stands for the central concept of social-ecological system resilience. Capacity, as an umbrella concept, has been divided into detailed sub-concepts. Although extensively discussed in specific fields, academia needs a systematic framework for deliberate differentiation among, and exploration into, different dimensions of capacity that simultaneously addresses capacity's links to governance. Lebel et al. [11] may fill this 
gap. They propose an analytical framework for the ways governance attributes affect society's capacity to manage resilience in regional social-ecological systems. They identify three sets of governance attributes: (1) participatory and deliberative; (2) polycentric and multi-layered; and (3) accountable and just. They divide capacity into six different dimensions ([11], Figure 1): (1) scale, or the capacity "to engage effectively with and handle multiple- and cross-scale dynamics"; (2) uncertainties, or the capacity "to anticipate and cope with uncertainties and surprises"; (3) fit, or the capacity "to design institutions which fit diverse social and ecological contexts"; (4) thresholds, or the capacity "to detect and navigate hard-to-reverse thresholds"; (5) knowledge, or the capacity "to combine and integrate different forms of knowledge"; and (6) diversity, or the capacity "to maintain ecological and social diversity". Lebel et al. [11] found strong associations between these three governance attributes and the six capacities for managing resilience.

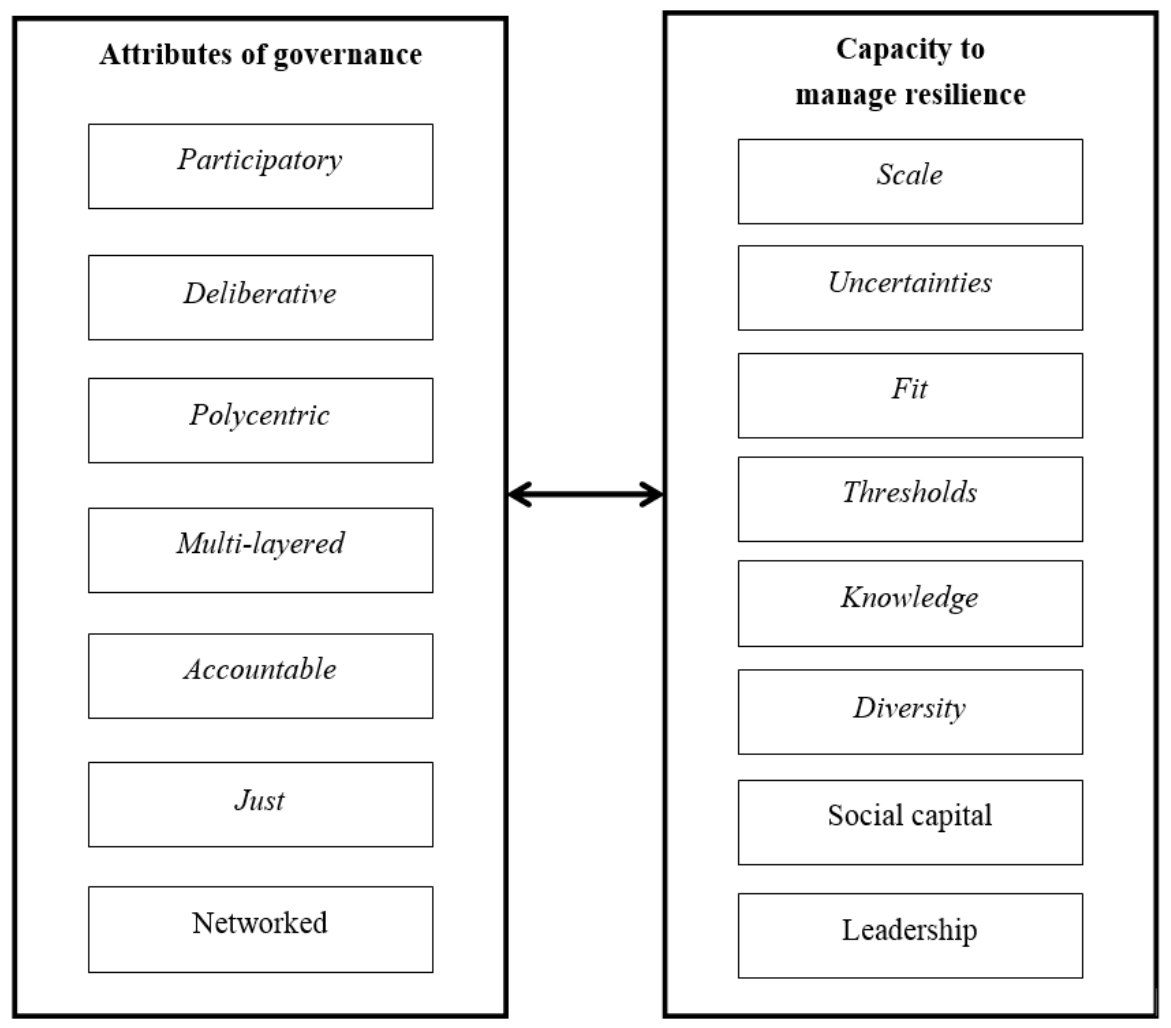

Figure 1. Framework representing associations between essential governance attributes and the capacity to manage resilience. Attributes and capacities analyzed by Lebel et al. [11] are in italics.

In an extensive review of the literature, Armitage [15] also summarized key attributes of adaptive, multi-level governance. Although Armitage did not differentiate capacity from governance attributes, his governance attributes may complement the framework proposed by Lebel et al. [11]. Specifically, Armitage's list of governance attributes includes participation, collaboration, deliberation, multiple layers, accountability, interaction, knowledge pluralism, and learning. These are attributes or capacities considered by Lebel et al. [11], although some differences in terms exist. On the other hand, three attributes summarized by Armitage [15], networked, leadership, and trust, are not explicitly addressed by Lebel et al. [11]. Given the importance of these three widely recognized features, I recommend 
amendments to the framework of Lebel et al. [11] by adding one more governance attribute, networked, and two more capacity dimensions: leadership and social capital. I use the term social capital instead of trust, because a social system needs trust to bond and bridge social networks. These networks and trust often constitute the concept of social capital [19].

\section{Research Approach}

This article traces and describes a long-term cross-level and cross-scale dynamics of the DFA social-ecological system from the late nineteenth century to present. For historical events, I drew on academic literature and official documents. The oral history method was adopted to include perspectives of marginalized social groups. To explore dynamics after the millennium, I used a variety of qualitative research methods, including in-depth interviews, focus groups, participant observations, and literature analysis. Field study spanned June 2012-June 2014. After summarizing the dynamic evolution of this system, I followed the modified framework shown in Figure 1 to describe attributes of the existing governance regime and its capacities for resilience.

\section{Cross-Scale and Cross-Level Dynamics of the DFA}

The focal social-ecological system of this study, the Danungdafu Forestation Area, geographically includes forest of 1138 hectares located in the rift valley of central Hualien County, eastern Taiwan $\left(23^{\circ} 36^{\prime} \mathrm{N}, 121^{\circ} 24^{\prime} \mathrm{E}\right.$, Figure 2$)$. As one of the few remaining forests in intensively developed lowland areas of eastern Taiwan, DFA may be a critical ecological corridor connecting protected areas in the Central Mountain Range and the East Coastal Mountain Range. As regards social system, the key characteristics that constructs the focal system is land rights debate, together with the relevant governance issues. The social system mainly consists of governmental agencies and local communities. Land property rights belong to the Taiwan Sugar Corporation, which has the central gonvernmental control over the majority of shares. The Forestry Bureau of central government takes charge of the management of forests. Buffering the DFA, there are seven local communities which are historically, socio-economically, culturally closely related to this piece of land. Populations of these communities has two main demographic sources: indigenous Amis people and Chinese-descent Han people. Some indigenous communities near DFA advocate that DFA is a traditional territory of social, cultural and economic significance. Therefore, they accordingly claim resumption of the land property rights [8]. Han people generally do not claim land property rights, but have a high expectation of being able to benefit from utilization of land and forests. Although the two populations have different views concerning land rights and different origins of cultural identity, they do share similar sense of belonging to the land of DFA, and are highly interested in governance issues. As Subsections 4.1-4.4 will show, such a sense of belonging is deeply rooted in the population's long-term connections to the land. Even though the ecological facet of the system had experienced two major transformations in the past century, the governance structure does show high continuity, in which local communities struggle to improve their well-being, and complex interrelationships among various communities and governmental agencies continue to exist. It is in this context that the land and forests of DFA, local communities, and relevant governmental agencies constitute the focal social-ecological system that is under investigation. 


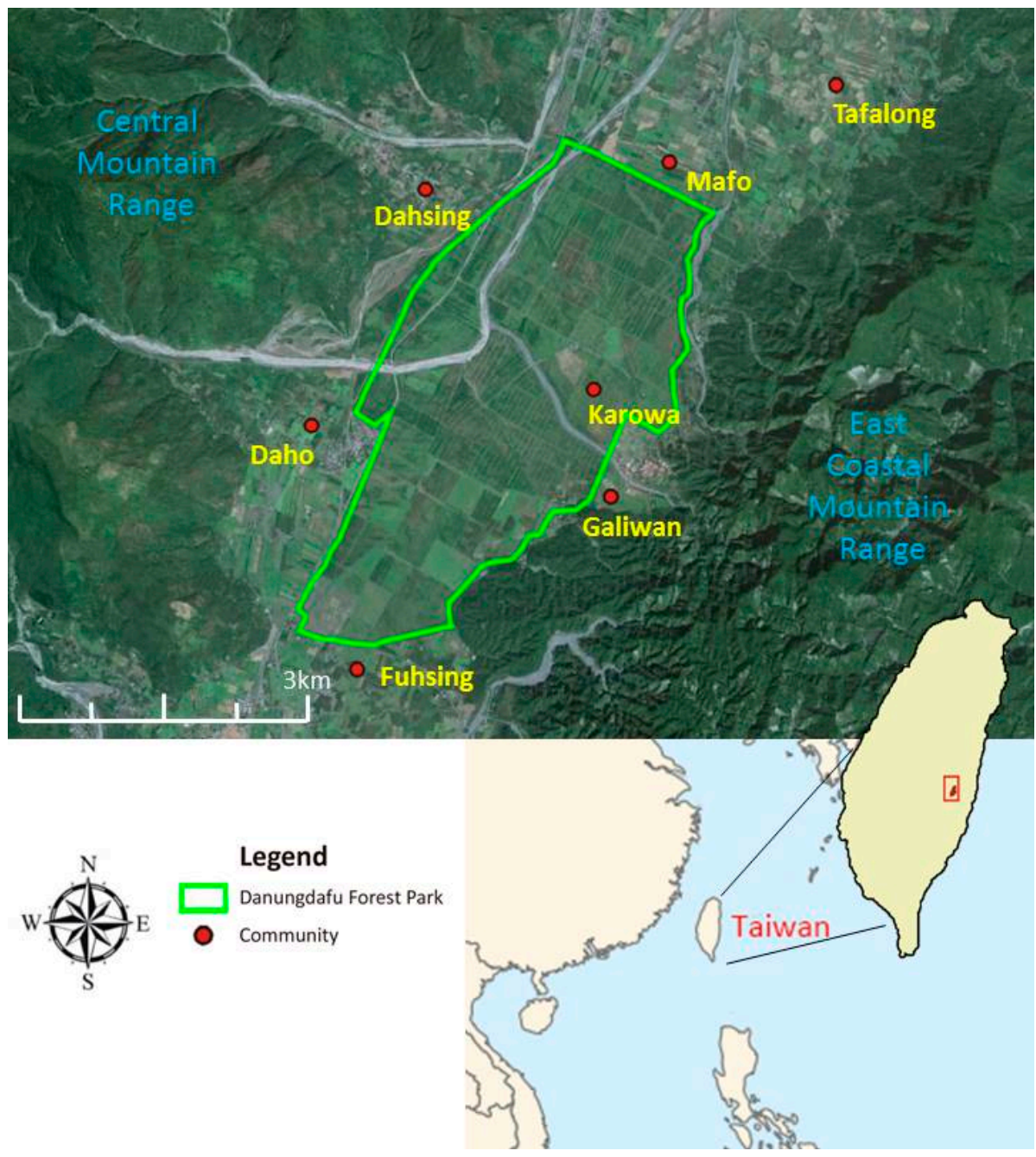

Figure 2. Map of the Danungdafu Forestation Area in eastern Taiwan. Satellite map data: Google earth 2013, 2013 Cncs/Spot Image Image 2013 DigitalGlobe.

Given the controversial nature and importance of DFA, the following question continues to be the focus of debate: how can DFA be governed to achieve sustainability goals? To answer this question, the first step is to identify main governance issues, drawing on full understanding of context, system dynamics and status quo [20]. Cash et al. [12] illustrated some scales and levels critical for understanding social-ecological system dynamics. Of these, spatial, jurisdictional, institutional, networks, and knowledge scales are closely related to the case of DFA. Relevant scales and levels are listed in the Table 1. I analyzed the dynamics of DFA following these subsections.

Table 1. Scales and levels critical for understanding the Danungdafu Forestation Area (DFA) case.

\begin{tabular}{cc}
\hline Scale & Levels (from low to high) \\
\hline Spatial & Patch, region, nation, globe \\
Jurisdictional & Community, regional, national \\
Institutional & Local institution, laws and regulations, constitution \\
Networks & Kin, community, bridging organizations \\
Knowledge & Specific, general \\
\hline
\end{tabular}




\subsection{From Forests to Sugar Plantation; 1895-1945}

Prior to Japanese rule of Taiwan from 1895 to 1945, the DFA was covered by bush forests interspersed with rivers and ponds. It provided wildlife habitat for large mammals, such as deer and wild boar, that were frequently hunted. Indigenous people of the Amis tribe, particularly the Karowa community, lived there, engaged in slash-and-burn farming, and hunted to sustain livelihoods and maintain their traditional common-pool resources regime [21,22]. Another Amis community, Tafalong, also used this land for livelihood and cultural festivals.

The shift in 1895 to Japanese rule fundamentally changed both human communities and the landscape of the DFA. The Japanese government regarded Taiwan as a source of natural resources and commodities production base for both domestic consumption and international trade. Cane sugar, a lucrative commodity at that time, required large areas of land. This constituted the main motive for legislation at the early stages of Japanese rule. New laws nationalized property rights of all "ownerless" land in Taiwan, most of which was Taiwan's indigenous people's traditional territory [23]. After nationalization, the government leased, under favorable terms, large areas of land to private enterprises, encouraging them to develop the land. This is the context of eastern Taiwan's inclusion in the development of a modern state [24].

In 1921, a Japanese private enterprise, Salt and Sugar Ltd., acquired use rights of DFA and began to expel the Karowa community of Amis people from DFA. Although indigenous people resisted the encroachment of these outsiders, their actions were futile under the massive pressure of the public authority of the government [22]. People in the Karowa community were forced to relocate to marginal lands and other indigenous communities around DFA, as well as other places in central Hualien County. The community virtually collapsed and lost most of their social networks and identity. Poor conditions of marginal lands contributed to the deterioration of livelihoods. The effects are still observable today [22].

From 1921 to 1945, cane sugar production in DFA increased steadily. The previous social-ecological system was transformed into a mono-culture of sugar cane and included in the international trade system [25]. Traditional indigenous common-pool resource institutions that once managed the ecosystem were replaced by the modern state regime.

The transformation of DFA also changed the demographic composition. The labor-intensive nature of cane sugar plantation and industry recruited large numbers of Chinese-descent workers from western Taiwan and China. These Chinese workers, usually called Han people, settled down to form several new settlements around DFA [25]. This explains why today's communities around DFA comprise two main demographics: indigenous people and Han people. These demographics shape the nature of today's collective actions. Some indigenous people were forced to or voluntarily served as sugar industry workers. This contributed to changes in the way indigenous people maintained their livelihoods. Dependence on the sugar industry characterized the economy and social life of communities surrounding DFA until the sugar industry collapsed in 2002.

The sugar plantation also changed the biophysical properties of DFA. Originally a flood plain its high groundwater level hindered maturation of sugarcane. Sponsored by the Japanese government, a drainage system was constructed. Soil improvement measures, such as fertilization and covering new soils from areas outside DFA, were introduced to sustain productivity. These measures were maintained 
and improved by the next political regime which began in 1945 [25]. The exact ways these measures affect the biophysical properties of DFA today require further study. Continued lowering of groundwater level has raised concerns of local residents and could become a major governance issue in the future.

\subsection{Rise and Fall of the Sugar Plantation: 1945-2002}

After the end of the Second World War in 1945, the central government of the Republic of China (ROC) took over all Japanese assets and state-owned land in Taiwan. The ROC policies further strengthened nationalization [26]. The DFA land and the Salt and Sugar Ltd.'s productive assets were nationalized in 1946 into the Taiwan Sugar Corporation, a public enterprise of the current Ministry of Economic Affairs. After a short period of restructuring due to war damage, the sugar industry had continuously increased production since 1947 [25].

For indigenous people, especially the Karowa community, the change in political regime did not change the nature of oppression exerted by the modern state. Some aspects even deteriorated. During Japanese rule, the Salt and Sugar Ltd. had not fully utilized all DFA land, because of resistance by indigenous people and a subsequent informal agreement with indigenous people in the early stages of Japanese rule. So some indigenous residents still lived and reclaimed approximately $40 \%$ of DFA land surrounding the sugar plantation. In 1953, however, the Taiwan Sugar Corporation began to expel residents still living in DFA. Therefore, the indigenous community suffered a second, and more thorough, wave of forced displacement that further deteriorated local livelihoods and community structure [22].

Throughout the 1950s, sugar became one of the Taiwan's most important export industries. Exports accounted for 41.1\%-79.8\% of Taiwan's total export value. After 1960, rapid industrial development meant sugar exports gradually played a smaller role in economy, even though they still made huge financial contributions to the government and its employees. Sugar production in DFA increased to a peak in 1980. Since the 1980s, the collapse of sugar prices in the international market and the rise of domestic production costs have seriously affected sugar production. Taiwan's membership into the World Trade Organization, valid since 2001, was the last straw. By 2002, sugar production in DFA completely ceased. The land was abandoned from cultivation [25].

With the rise and fall of the sugar industry, the population of Han people in surrounding communities experienced a similar trend. The Daho community, a typical settlement of sugar industry workers, had 6000 people during the peak, but only a few hundred residents live there today. Migration of young people to urban areas caused a huge shortage of human capital, which severely limits governance capacity. This pattern is true for every community neighboring DFA.

Under ROC's authoritarian political regime, before the mid-1980s, local DFA communities obediently followed the jurisdictional and institutional arrangements. During 1980s, however, the rise of the democratic and social movements motivated some indigenous intellectuals to initiate the "Return My Land Movement" in which indigenous tribes began to claim traditional territories [27]. Inspired by the movement and understanding to the history of his own community, a young man of the Karowa community, Anaw Lo'oh Pacidal, begun to organize at the end of the 1980s, initiating a series of protests throughout the 1990s [8]. Lack of a friendly institutional framework or support from broad social networks prevented progress in his kinship-based protest initiative. 


\subsection{Forestation: 2003 to Present}

Evolution of the DFA social-ecological system in the current post-sugarcane phase is deeply affected by changes in: (1) forestation policy; (2) the institutional framework regarding indigenous affairs; (3) community development and community forestry policy; and (4) tourism development policy. In the following paragraphs, I describe the impacts of these trends and the interactions among them.

Changes in forestation policy have fundamentally shaped today's ecological system at DFA. Since 2001, the ROC government has promoted the "Afforestation Policy in the Plain Area". Policy objectives include using agricultural land released by accession to WTO to provide ecosystem services, such as environmental aesthetics and carbon sequestration, and increase domestic timber production [28,29]. In 2001, the Taiwan Sugar Corporation owned most of the idle land. Being a public enterprise, it actively cooperated with national policy. Beginning in 2003, the DFA was quickly transformed into a forestation area. In the rush to achieve forestation goals assigned by the ROC government, afforestation in DFA was implemented improperly. Sapling species were chosen and planted depending on availability in the sapling market. Perspectives of stakeholders, especially surrounding communities, were not considered. These problems raised a serious question: could this afforestation project achieve policy objectives in a meaningful way? It is unlikely that such random planting can fulfill any specific policy objective, such as economically efficient use of land, environmental aesthetics, carbon sequestration, or timber production.

The transformation of DFA in 2003 did not consider the controversial nature of land property rights. This issue has increasingly become focus of concern, thanks to the indigenous "Return My Land Movement" and the subsequent changes in institutional consideration of indigenous affairs. A constitutional amendment in 1997, and passing the Indigenous Peoples Basic Law in 2005, recognizes and protects indigenous rights to land and natural resources in traditional territories [30,31]. These laws are the fundamental institutional framework from which many indigenous initiatives lay claim to traditional territories. The Karowa community, led by Anaw Lo'oh Pacidal, resumed to ongoing protest national policies in the first decade of Twenty-first Century. This time, the community formed extensive alliances with indigenous and environmental movement non-governmental organizations to fight for land tenure. Although their actions have not changed the afforestation policy in DFA, they did made a small step toward achieving land rights because of the support of friendlier institutions and bridging organizations. As a symbol of their inherent rights, the Karowa people successfully rented a small piece of land, establishing a resistance stronghold in the middle of the community's original location [8]. Even now, however, the Taiwan Sugar Corporation insists that DFA is its legitimate property.

During 1990s, Taiwan's national policies began to change toward decentralization due to international paradigm shifts and identified faults of the state-centric regime. Since the millennium, every community surrounding DFA was affected by a new national community development policy by the national government, namely the "Community Empowerment". Originally initiated in 1994, this policy aimed to empower local communities and to promote community-based governance, usually by focusing on local cultural, socio-economic and environmental issues [32]. Under the financial and administrative supports of the national government, every community in DFA established its own 
community development association, sometimes more than one in a community, which is responsible for self-governance.

Almost parallel to the expansion of the community empowerment policy, another new policy also began to exert its influence on these communities. In 2002, influenced by the international trends towards decentralization and participation in environmental governance, the Forestry Bureau initiated the "Community Forestry" policy to promote community-based environmental governance. This policy focused on, but was not limited to, nature conservation and ecotourism [33]. Through the local community development associations, most local communities in DFA have participated in the Community Forestry projects. This participation is directly related to recent tourism development policy.

The tourism development policy is a part of the 12 large-scale economic development plans developed in 2007 by President Ma Ying-Jeou. These plans include extension of the Afforestation Policy in the Plain Area and construction of three large forest parks for tourism development. One of these three parks is DFA, now renamed the Danungdafu Forest Park, and developed to include many additional recreation facilities. The Foresry Bureau took charge of promoting the policy. At the regional level, the bureau's Hualien Branch is responsible for managing the forest park. The park plan and the way the government carried out the plan, offended the Karowa community [34]. As in the past, there was no real participotory and deliberative processes from planning implementation. Indigenous land rights and cultural identity issues were not on the agenda. This time, another indigenous community, Tafalong, joined the protest, inspired by the prevailing indigenous rights movement and its alliance with many indigenous organizations in eastern Taiwan. Karowa, Tafalong and numerous bridging organizations successfully launched a protest during the opening ceremony of the new DFA on 25 May 2011, attracting nationwide attention via media reports.

After the event, public opinion and pressure from their superiors forced the management agency to offer opportunities for participation and collaboration. A meeting was held and attended by all communities surrounding DFA, but it fell apart due to heated debate among communities and the management agency. From 2011 to the present, however, cooperation between the management agency and some communities has strengthened, especially for specific community forestry projects promoting ecotourism. Some communities have also tried to develop a closer inter-community cooperation in the past two years.

Failure of the 2011 meeting can be explained. The management agency was not authorized to deal with fundamental issues such as indigenous land rights and the governance framework. Some people questioned this, concluding that meaningful changes were not possible. To make matters more complicated, there are seriously divergent views among the communities. The temporary alliance between the Karowa and Tafalong communities broke soon after the protest because both claimed ownership of the land tenure and could not reach an agreement.

For communities mainly composed of Han people who were deeply affected by the collapse of sugar industry, the main concerns were improvement of livelihood, not land tenure. These communities include Mafo, Daho, Galiwan, Dahsing, and Fuhsing. They are basically happy with the government's plan to transform forests into a forest park with tourism potential, although they also complain that the government has never provided adequate opportunities for local communities to participate in decision-making processes. Furthermore, these communities do not want open conflict with the government. Under the Community Empowerment and Community Forestry policy, these communities have obtained a number of government projects. 


\subsection{Summary of Cross-Scale and Cross-Level Dynamics}

As many social-ecological systems have experienced around the world, transformation were triggered by external drivers related to changes in political jurisdiction at the state level and by economic drivers of international trade at the global level [13]. This change follows introduction of modern state-centric jurisdiction and institutions to replace traditional, local common-pool resources institutions. The history of changes in political jurisdiction fundamentally changed both the ecological and human communities of DFA, the DFA regional social-ecological system. The same global economic and political drivers dominated the evolution of DFA from 1895 to 2002. Both Japanese and ROC governments used DFA land for global market and national economic development, usually at the expense of local communities. Termeer et al. [17] state this is how a typical monocentric governance regime evolves. This regime is characterized by the sole management authority of a central government having only one jurisdictional level ([17], Table 1). Throughout the Twentieth Century, there was only top-down influence in Taiwan, i.e., the national government. Under the authoritarian regime, local communities were continuously disintegrated and displaced. Until recently, these neither dared nor had the consciousness and capacity to take bottom-up collective action. Only one community was the exception, but their weak, kinship-based action was eventually futile.

At the beginning of the Twenty-first Century, global economic drivers and the monocentric governance regime led to a second transformation. Once again, it was top-down, failing to consider local concerns or use a true participatory, deliberative decision-making process. This time, however, the transformation decision was based on both nation-wide economic and environmental aspects. The initiative for carbon sequestration even cited global concerns, regardless of the feasibility of this argument for DFA. Probably more critical difference is that two decades of democratic and social movements have produced much stronger nation-wide networks and a somewhat friendlier institutional framework. This has fostered the emergence of numerous local institutions and bottom-up initiatives. Therefore, two indigenous communities were able to strongly challenge the existing governance regime. Other communities challenged it in a very moderate way. These challenges were attempts to give feedback on management issues by upper jurisdictional levels.

The management agency in charge of the Forest Park, the Hualien Branch of the Forestry Bureau, supervises and guides the five communities implementing community forestry projects. As a result, two-way communication and feedback is rare between the two jurisdictional levels. As for the challenges of the Karowa and Tafalong communities, the park management agency avoids responding to their demands as much as possible. This attitude also applies to the Taiwan Sugar Corporation and its Hualien branch. As a result, severe hostility and distrust between community and government agencies prevail.

At the community level, inter-community interactions also rarely happen. Local communities are traditionally accustomed to focus on their own issues. They are rarely aware that, in a multi-scale and multi-level world, dealing with their own affairs requires multi-party cooperation. This focusing on their own claims usually hinders communication and slows the building of cooperative relationships among communities. An obvious example is land claims of the two indigenous communities, which have caused division between the two indigenous communities, and alienation with five other communities. The other five communities focus on livelihood improvement and specific management issues. They are basically willing to work with the park management agency. This attitude makes the 
two indigenous communities think that other communities are not sympathetic enough with historical oppression suffered by indigenous communities. As a result, trust relationships among communities are either very fragile or non-existent. Hardly any information and knowledge exchange or collective action is observed.

For the lengthy processes of local institution building, all surrounding communities are severely limited by lack of human capital and support networks. This applies to revitalization of traditional institutions in indigenous communities, or emergence of new institutions in other communities. In turn, it limits the ability of initiating intra-community and inter-community collective action.

Finally, the Community Empowerment and Community Forestry policies do show some results, but have some faults. In general, they have good intentions and have made some contribution to local capacity and institution building. Their community-based nature, however, has limited the scope of community actions and vision. Communities were restricted to independently addressing issues within their spatial or institutional jurisdiction. The Forestry Bureau is aware of this problem and has begun to promote inter-community cooperation in the past two years. Real progress remains very limited.

All previously mentioned cross-scale and cross-level dynamics shaped DFA's current governance structure. Figure 3 summarizes actions and interactions among and within different jurisdictional levels. Actions may include command, supervision, guidance, claims making, protest, deliberation, and negotiation.

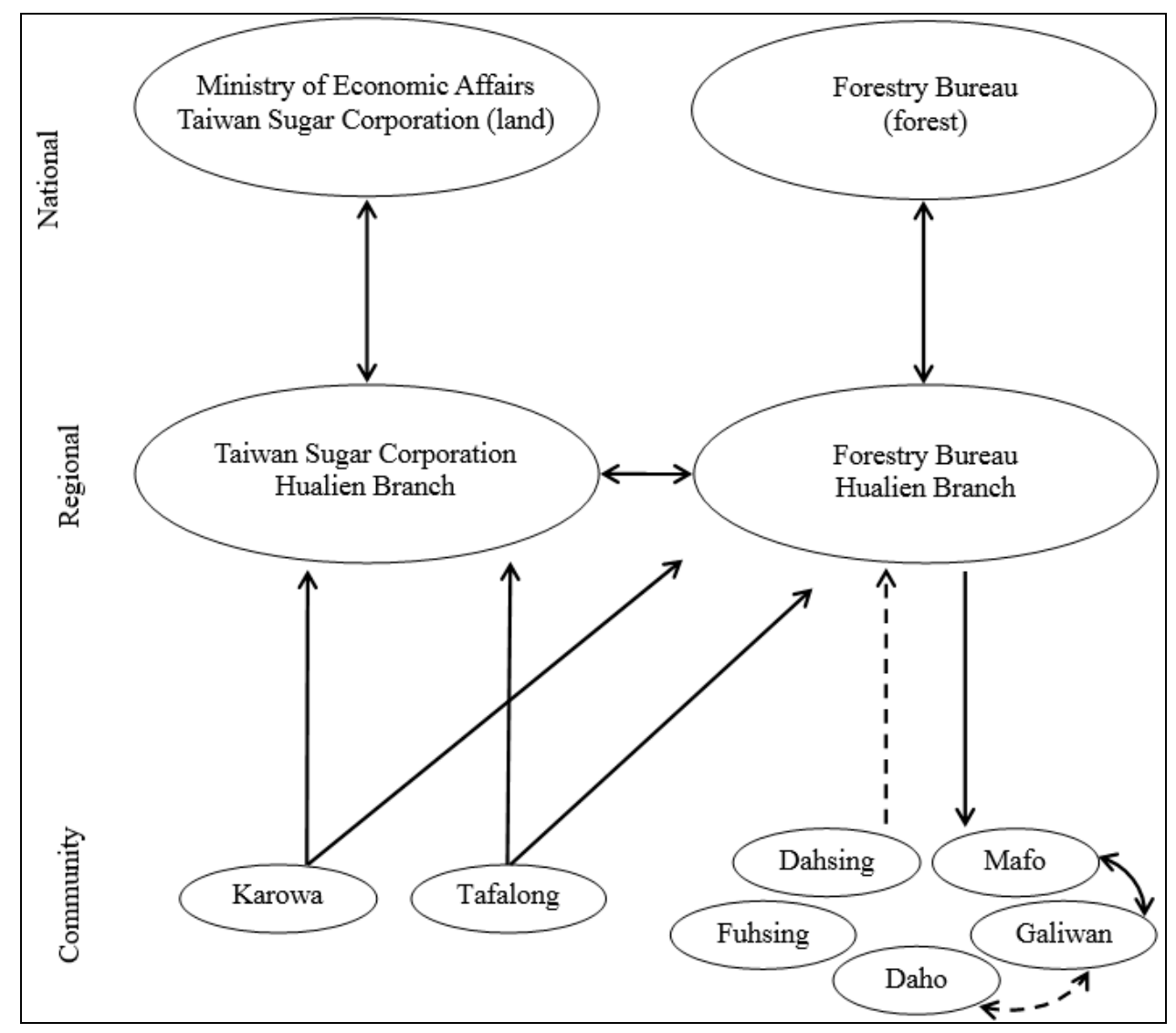

Figure 3. Current governance structure of DFA at national, regional and community levels. Solid Arrows indicate strong interactions and dashed arrows indicate weak interactions. Arrows indicate direction of interactions. Absence of arrow denotes no interaction. 


\section{Governance Attributes and Capacities to Manage Resilience of DFA}

In this section I apply the modified framework in Figure 1 to governance attributes and capacity of the DFA.

\subsection{Governance Attributes}

Participatory and deliberative. There is a growing consensus that non-state stakeholders need to be involved in the processes of environmental governance. Governance processes include discovering problems, setting agendas, and implementation. Participation helps fulfill the requirement of democratic legitimacy. Participation helps generate critical information for good governance and considers an expanded scope of the knowledge system, diverse interests, and values [11,35]. Deliberation highlights the importance of open communication, discussion, and reflection processes among different stakeholders [11]. The current governance regime of DFA rarely meets the requirements of participation and deliberation. Decision-making for forestation, building the forest park, and formulation of relevant programs, came directly from the policy directives and bureaucratic administrative systems of the national government. It did not include participation and deliberation of non-state actors. Even during implementation, public involvement remains confined within a very limited range. Through community forestry projects, communities have participated in some detailed management issues of the master plan, such as ecological monitoring and ecotourism development. Amendment and discussion of the master plan, however, is still not on the agenda for public participation and deliberation. Communities, non-governmental organizations, and academia were excluded from most decision-making and implementation processes. Currently, no formal or informal mechanisms exist for deliberation that includes non-state participation.

Polycentric. The DFA governance structure is characterized by a monocentric authority, not a polycentric institution. The fact that forest and land are managed by separate jurisdictions does not change things, because the Taiwan Sugar Corporation always adheres to national policy. For a small area like DFA, polycentricity may not be an issue of major concern. Polycentric institutions are designed to adapt to spatially heterogenous contexts.

Multi-layered. The DFA governance structure currently has three jurisdictional levels: (1) national government; (2) regional management agency of DFA responsible for dutiful implementation of national policies; and (3) community-level institutions still in their infancy. Functionally, it is a two-tier structure with a dominant state and weak community. This is a moderate version of the stereotypical dominance pattern classified by Young [14]. Can this structure deal with scale-dependent challenges and cross-scale interactions [11]? Basically, the answer is no. As shown in Section 4, the national government, its policies, and its agents consider land use options mainly from national or global perspectives. The forestation policy is a typical example. The policy itself, and the way the policy was carried out, overlook the social-ecological settings of DFA. Local communities and academia have asked some fundamental questions: such as whether DFA biophysically suitable for timber production and carbon sequestration and how a democratic government can repeat the actions of the past authoritarian regimes pursuing national goals at the expense of local needs and inherent rights. When the current state government does discover and tries to fix this imbalance, its community-based policies 
overemphasize on community-level management issues, as do the communities themselves. In some cases, communities have made proposals without considering possible negative externalities. As Berkes [13] has highlighted, states and communities usually define issues from the perspective of their own level, without considering perspectives of other levels. What makes matters worse is the lack of effective cross-level linkages. The state dominates decision-making and implementation. It is reluctant to devolve authority to or receive feedbacks from other levels. This fundamentally limits possible emergence of multi-layered governance. Issues at DFA can rarely be addressed at suitable spatial and institutional levels, nor can they be adequately addressed by appropriate cross-scale and cross-level linkages. Therefore DFA represents a typical example of scale mismatch in which institutional arrangements do not fit the social-ecological system boundary [13,36].

Accountable. Accountability, by definition, means the processes and mechanisms through which actors are responsible for providing information and indicating the basis of decision-making and actions to the point of being punished when there is misconduct [37]. This concept can be divided into upward and downward accountability [11]. In the case of DFA, upward accountability exists, as usually happened in other cases. At DFA, local communities are obliged to be accountable to authorities at upper levels, via a wide range of governmental regulations and projects. Other than a few superficial public hearings triggered by indigenous movements and the subsequent public pressure, downward accountability is virtually non-existent.

Just. Given the governance attributes of DFA, it is reasonable to expect unjust distribution of benefits and involuntary risks to last for a very long time. The forests of DFA do generate some public goods, common-pool resources, and economic benefits, but local communities, especially the historically oppressed and currently vulnerable indigenous groups, bear most of the structure- and policy-induced costs. These people have lost their land tenure, their use rights, and their minimal rights of being formally included in the governance regime.

Networked. The attribute networked refers to whether and how different stakeholders come together to deal with governance issues. Recent research $[19,38]$ has shown that social network patterns exert important influences on governance processes and outcomes. Bodin and Crona [19] list five main network characteristics affecting governance: number of ties, degree of network cohesion, subgroup inter-linkages, network centralization, and actor centrality. According to these characteristics, DFA represents a highly centralized network pattern, in which government agencies are the central actors loosely connected to the relatively isolated local actors (Figure 3). Although high network centrality may help solve simple problems, it may not be appropriate for dealing with complexities common in social-ecological systems, such as DFA. On the other hand, local actors are isolated and weak. There are few social ties among the isolated communities. Between the two clearly distinguishable subgroups (indigenous and Han) there is poor network cohesion. There are hardly any bridging ties for subgroup inter-linkage. This lack of ties, cohesion and inter-linkage, is generally considered to have negative effects on the formation of trust relationships, informational and intellectual exchange, collective action, and good governance. These negative effects are clearly shown in Subsection 4.4. 


\subsection{Capacity to Manage Resilience}

To manage social-ecological systems for resilience, a number of capacity dimensions are needed as Lebel et al. [11] and Figure 1 suggest. In the following analysis of the capacities of the governance regime at DFA, I follow the interpretations and terminology of Lebel et al. [11], except for the addition of social capital and leadership.

Knowledge. Knowledge is the capacity "to combine and integrate different forms of knowledge" [11], which represent a precondition for the conservation of biodiversity and cultural diversity [39]. At DFA, indigenous traditional knowledge has never been acknowledged by or included in the governance regime. Indigenous communities have used their food forest tradition and memories from the pre-state era to propose improvement ideas for combined forest and land use options that recover both biological and cultural diversity. Other local communities have also provided proposals based on their local knowledge of ecosystems and water scarcity. They, too, have not received attention from government authorities. The modern academic knowledge system usually enjoys an authoritative status in Taiwan, but only a small part of it (i.e., forestry) has played a role in decision-making and implementation processes. In recent years, some academic research projects have included multi-disciplinary perspectives. Right now, it is hard to expect today's governance regime, especially the central actors, to not only recognize the importance of integrating different knowledge systems, but also to take action to include them into governance processes. Only when fundamental governance attributes, such as participation and deliberation, improve can the flaws in knowledge capacity be corrected.

Diversity. The ignorance and unwillingness of knowledge seriously affects "diversity", the capacity "to maintain ecological and social diversity" [11]. Indigenous knowledge system, institutions, and cultural identity have suffered serious loss. If this trend remains unchanged, eventually indigenous communities will be lost as a vital source of renewal and reorganization in the DFA system. Despite hasty decision-making and implementation processes, forestation policies have contributed to the recovery of species diversity. The monoculture nature of forestation and the governance processes that ignore different knowledge systems, will eventually limit the extent to which biological diversity can recover.

Uncertainties. Uncertainties represents the capacity "to anticipate and cope with uncertainties and surprises" [11]. This needs an attitude open to accept change and the ability to learn by doing. Government agencies tend to maintain the status quo of national policies. They do not tend to face the possibility of change or accept views from different knowledge systems. They especially do not develop the double- or triple-loop learning central to adaptive governance [40]. A few experiments at the level of single-loop learning have been carried out via community-based projects. The premise of these experiments is that the existing forest park and governance structure will remain unchallenged.

Thresholds. Thresholds means the capacity "to detect and navigate hard-to-reverse thresholds" [11]. The existing governance regime, through cross-level interaction, discovered a few possible thresholds, such as overexploitation of some wildlife species as a result of poaching. The regime, however, remains insensitive and unresponsive to upcoming thresholds, such as collapse of the indigenous knowledge system, alteration of land tenure by legislation of the Indigenous Land and Ocean Act, and planning for a new freeway that will run through the DFA. 
Scale and fit. The closely related scale and fit represent the capacity "to engage effectively with and handle multiple- and cross-scale dynamics" and the capacity "to design institutions which fit diverse social and ecological contexts", respectively [11]. Using the scales and levels shown in Table 1, the current governance regime in DFA has fundamental flaws, as indicated in Subsection 5.1. Government authorities are mainly concerned about national and global spatial scales, national jurisdictional scales, laws and regulations (institutional scale), and general knowledge. Local communities, whether because of their inherent nature or because of community-based governance projects, focus on patch spatial scales, community jurisdictional scales, local institutional scales, kin or community network scale, and specific knowledge. Between national and local communities, there are no intermediate or bridging institutions and few effective cross-scale and -level linkages to fit the DFA social-ecological system.

Social capital. Social capital is an important capacity contributing to sound environmental governance [41,42]. Specifically, it includes bonding and bridging networks, and trust among individuals and groups of people [19]. Currently, each local community in DFA has its own bonding networks, mainly kinship-based. Among communities, bonding relationships are very weak (see Subsection 4.4). Two indigenous communities have developed their own bridging networks with non-governmental organizations, but the other communities are very weakly connected. As mentioned in Subsection 4.4, hostility and distrust prevail among the two indigenous communities and government agencies. Alienation is obvious between indigenous and Han communities. The fragile state of social capital has historical and governance roots.

Leadership. Good leadership with human skills and agency are needed for adaptation and transformation towards sustainability [43-45]. Westley et al. [43] list the fundamental skills contributing to successful ecosystem stewardship: "facilitating knowledge building and utilization; vision building; developing social networks; building trust, legitimacy, and social capital; facilitating/developing (social) innovations; preparation and mobilization for change; recognize or create and seize windows of opportunity; identifying and communicating opportunities for 'small wins'; and facilitate conflict resolution and negotiations". In DFA, a few community leaders have some of these skills, but they have almost exclusively been applied to community-level issues. So far, no leaders have emerged with the vision and skills for transformation at the DFA or higher system perspective. This includes governmental officials. Some bridging organizations and individuals are involved in governance of DFA, but mainly in collaborative roles. But still, none has lead or shown a willingness to lead in transformation.

\section{Conclusions and Policy Implications}

Resilience thinking has strongly influenced how people understand and pursue sustainably linked social-ecological systems. Resilience thinking highlights the need to build capacity and manage general system properties in a complex, constantly changing world. I addressed social-ecological system governance, and explored associations between cross-scale and cross-level dynamics, governance attributes, and capacities to manage resilience in the social-ecological system of DFA. Based on previous studies [11,15], I propose a modified analytical framework that permits analysis of associations among essential governance attributes and the capacities to manage resilience. There are 
two main conclusions from this Taiwanese example of a social-ecological system: the modified framework was useful and it helped identify flaws in current governance.

The modified framework, when supported by an in-depth investigation into cross-scale and cross-level dynamics, can be useful for understanding how current capacities for managing resilience are related to fundamental governance attributes. Generally, capacities to manage resilience are greatly influenced by governance attributes. Governance attributes are the outcomes of the long-term dynamics of history, politics, ecology, society and economy. Thus, at DFA, there is an obvious path-dependence phenomenon.

The modified framework helped identify fundamental flaws of the current governance regime, including key issues needing to be addressed. Overall, the governance regime of DFA was characterized as (1) non-participatory and non-deliberative; (2) monocentric with a two-tier structure of dominant state and weak communities; (3) upward accountability and unjust; and (4) very loose networks. These attributes help explain the serious defects in DFA governance. The current governance regime has extremely limited capacities in knowledge, diversity, uncertainties, thresholds, social capital, and leadership. The current governance regime shows a mismatch in scale and fit dimensions. According to the classification of Termeer et al. [17], this governance regime is a traditional monocentric regime. Although it has recently begun to attempt to include the limited contents of multilevel governance, it is still far away from genuine multilevel governance. In particular, hardly any of the actors, whether government authorities or local communities, have begun to learn and recognize the importance of adaptive governance. As Termeer et al. [17] emphasize, scale-sensitive governance regimes are needed for adaptation to complex social-ecological conditions.

What can be done to improve current governance attributes and capacities of the studied governance regime? Analysis in Subsection 5.2 indicates a critical starting point: government and local communities should recognize that the multi-scale and multi-level interactive world means their individual and separate capacities are far from sufficient to deal with complex challenges. This system needs to navigate toward a governance regime that is more participatory, deliberative, multi-layered, accountable, just, and networked. This can be done by developing an intermediate institution to coordinate cross-scale and cross-level interactions in ways that may more adequately fit the DFA social-ecological system. Numerous empirical examples around the world have shown the value of these intermediate institutions [13,46-48]. In the DFA, the government should upgrade its community-based policy to a regional social-ecological system governance policy that encourages bottom-up participation of local communities in governance. As part of its top down action, the government should admit to the historically unjust nature of current land tenure and dominant governmental power. By creating a reconciliation atmosphere, the government can facilitate subsequent negotiation, collaboration, and transformation. Equally important, the government should eventually devolve part of its authority to other governance levels, depending on the nature of the governance issue. This awareness, consensus, and external institutions should be cultivated to create a friendly environment from which innovative and adaptive governance initiatives can emerge to function successfully.

\section{Acknowledgments}

The author is heartily grateful for the team work and inspiration provided by all research team members in the joint research project titled "Social-ecological system resilience and adaptive 
co-management: an experimental pioneer study in Taiwan". This article presents part of the results of a subproject titled "Social-ecological system resilience and adaptive co-management: origins, interplay and changes of resilience and governance institutions", and financed by research grants from National Dong Hwa University (101T927-3; 102T929-5; 103T929-5) and the Ministry of Science and Technology, Taiwan (NSC 102-2621-M-259-001; MOST 103-2621-M-259-004). I thank these two institutions for their support. Special thanks are given to all interviewees, including community residents, government officials, non-governmental organization practitioners, and scholars, for their generous supports and feedback. I am also heartily grateful for the two anonymous reviewers for their insightful comments and suggestions.

\section{Conflicts of Interest}

The author declares no conflict of interest.

\section{References}

1. Brundtland, G.H. Report of the World Commission on Environment and Development-Our Common Future; United Nations General Assembly: New York, NY, USA, 1987.

2. Anderies, J.M.; Folke, C.; Walker, B.; Ostrom, E. Aligning key concepts for global change policy: Robustness, resilience, and sustainability. Ecol. Soc. 2013, 18, Article 8.

3. Holling, C.S. Understanding the complexity of economic, ecological, and social systems. Ecosystems 2001, 4, 390-405.

4. Folke, C.; Carpenter, S.R.; Walker, B.; Scheffer, M.; Chapin, T.; Rockström, J. Resilience thinking: Integrating resilience, adaptability and transformability. Ecol. Soc. 2010, 15, Article 20.

5. Chapin, F.S., III; Folke, C.; Kofinas, G.P. A framework for understanding change. In Principles of Ecosystem Stewardship: Resilience-Based Natural Resource Management in a Changing World, 1st ed.; Chapin, F.S., III, Kofinas, G.P., Folke, C., Eds.; Springer: New York, NY, USA, 2009; pp. 3-28.

6. Walker, B.; Holling, C.S.; Carpenter, S.R.; Kinzig, A. Resilience, adaptability and transformability in social-ecological systems. Ecol. Soc. 2004, 9, Article 5.

7. Chapin, F.S., III; Carpenter, S.R.; Kofinas, G.P.; Folke, C.; Abel, N.; Clark, W.C.; Olsson, P.; Smith, D.M.S.; Walker, B.; Young, O.R.; et al. Ecosystem stewardship: Sustainability strategies for a rapidly changing planet. Trends Ecol. Evol. 2009, 25, 241-249.

8. Hwaung, Y.-H. Multiple Boundaries as Palimpsests: The Landscapes of Native Title in Taiwan. Ph.D. Thesis, National Dong Hwa University, Hualien, Taiwan, 2014. (In Chinese)

9. Lemos, M.C.; Agrawal, A. Environmental governance. Annu. Rev. Environ. Resour. 2006, 31, 297-325.

10. Young, O.R. The effectiveness of international institutions: Hard cases and critical variables. In Governance without Government: Order and Change in World Politics; Rosenau, J.N., Czempiel, E.-O., Eds.; Cambridge University Press: Cambridge, UK, 1992; pp. 160-196.

11. Lebel, L.; Anderies, J.M.; Campbell, B.; Folke, C.; Hatfield-Dodds, S.; Hughes, T.P.; Wilson, J. Governance and the capacity to manage resilience in regional social-ecological systems. Ecol. Soc. 2006, 11, Article 19. 
12. Cash, D.W.; Adger, W.N.; Berkes, F.; Garden, P.; Lebel, L.; Olsson, P.; Pritchard, L.; Young, O. Scale and cross-scale dynamics: Governance and information in a multilevel world. Ecol. Soc. 2006, 11, Article 8.

13. Berkes, F. From community-based resource management to complex systems: The scale issue and marine commons. Ecol. Soc. 2006, 11, Article 45.

14. Young, O. Vertical interplay among scale-dependent environmental and resource regimes. Ecol. Soc. 2006, 11, Article 27.

15. Armitage, D. Governance and the commons in a multi-level world. Int. J. Commons 2008, 2, $7-32$.

16. Gibson, C.C.; Ostrom, E.; Ahn, T.K. The concept of scale and the human dimensions of global change: A survey. Ecol. Econ. 2000, 32, 217-239.

17. Termeer, C.J.A.M.; Dewulf, A.; van Lieshout, M. Disentangling scale approaches in governance research: Comparing monocentric, multilevel, and adaptive governance. Ecol. Soc. 2010, 15, Article 29.

18. Wilson, J.A. Matching social and ecological systems in complex ocean fisheries. Ecol. Soc. 2006, 11, Article 9.

19. Bodin, Ö.; Crona, B.I. The role of social networks in natural resource governance: What relational patterns make a difference? Glob. Environ. Chang. 2009, 19, 366-374.

20. Resilience Alliance. Assessing Resilience in Social-ecological Systems: Workbook for Practitioners, Version 2.0, 2010. Available online: http://www.resalliance.org/3871.php (accessed on 13 August 2014).

21. Chang, T.-Y.; Tsai, B.-W. Indigenous Traditional Territory: Research Report, 1st ed.; Council of Indigenous People, Executive Yuan: Taipei, Taiwan, 2003. (In Chinese)

22. Hwaung, Y.-H. Hometown of Others: On Displacement and Autonomy Movement of Karowa Indigenous People from the Perspective of Space Hegemony. Master's Thesis, National Dong Hwa University, Hualien, Taiwan, 2003. (In Chinese)

23. Shizue, F. Governing Indigenous People: The Plan of Governing Taiwan by Japan, 1st ed.; WenYingTang: Taipei, Taiwan, 1997. (In Chinese)

24. Lin, S.-C. Land and Settlement Development in Central East Rift Valley: 1800-1945. Master's Thesis, National Taiwan Normal University, Taipei, Taiwan, 1995. (In Chinese)

25. Chung, S.-H. A History of the Development of Cane Sugar Industry in Hualien: 1899-2002, 1st ed.; East Taiwan Research Association: Taitung, Taiwan, 2009. (In Chinese)

26. Liu, N.-Y. Notes on Taiwan's Land Reform; Literature Institute of Taiwan Province: Nantou, Taiwan, 1989. (In Chinese)

27. Parod, I., Ed. Archives of the Taiwan Indigenous Movement; Council of Indigenous People and Institute of National History: Taipei, Taiwan, 2008. (In Chinese)

28. Lin, K.-C. The analysis of the afforestation policy in the plain area. Taiwan. Agr. Econ. Rev. 2003, 8, 111-140. (In Chinese)

29. Chen, A.-H.; Chen, L.-M. Promoting the afforestation policy in the plain area. Taiwan For. J. 2002, 28, 18-21. (In Chinese)

30. Yapasuyongu Poiconu. United Nations declaration on the rights of indigenous peoples and protection of Taiwan indigenous rights. J. Taiwan. Ind. Stud. 2007, 2, 141-168. (In Chinese) 
31. Huang, S.-M. Globalization and the change and status quo of fundamental indigenous policy in Taiwan. In Government Policy and Social Development among Taiwanese Indigenous Peoples, 2nd ed.; Huang, S.-M., Chang, Y.-H., Eds.; Institute of Ethnology, Academia Sinica: Taipei, Taiwan, 2010; pp. 15-50. (In Chinese)

32. Chen, L.-C. Recent development of community empowering in Taiwan. J. Hous. Stud. 2000, 9, 61-77. (In Chinese)

33. Lu, D.-J. Indigenous people and community forestry. Taiwan J. For. Sci. 2009, 16, 28-30. (In Chinese)

34. Hwaung, Y.-H. Indigenous traditional territory? National territory tradition? Enlightenment of a dialogue. Cul. Stud. Bimonth. 2012, 132, 69-87. (In Chinese)

35. Bulkeley, H.; Mol, A.P.J. Participation and environmental governance: Consensus, ambivalence, and debate. Environ. Values 2003, 12, 143-154.

36. Cumming, C.S.; Cumming, D.H.M.; Redman, C.L. Scale mismatches in social-ecological systems: Causes, consequences, and solutions. Ecol. Soc. 2006, 11, Article 14.

37. Schedler, A. Conceptualizing accountability. In The Self-Restraining State: Power and Accountability in New Democracies; Schedler, A., Diamond, L., Plattner, M.F., Eds.; Lynne Rienner Publishers: London, UK, 1999; pp. 13-28.

38. Bodin, Ö.; Crona, B.I.; Ernston, H. Social networks in natural resource management: What is there to learn from a structural perspective. Ecol. Soc. 2006, 11, Article 2.

39. Rozzi, R. Biocultural ethics: From biocultural homogenization toward biocultural conservation. In Linking Ecology and Ethics for a Changing World: Values, Philosophy, and Action; Rozzi, R., Pickett, S.T.A., Palmer, C., Armesto, J.J., Callicott, J.B., Eds.; Springer: New York, NY, USA, 2013; pp. 9-32.

40. Kofinas, G.P. Adaptive co-management in social-ecological governance. In Principles of Ecosystem Stewardship: Resilience-Based Natural Resource Management in a Changing World, 1st ed.; Chapin, F.S., III, Kofinas, G.P., Folke, C., Eds.; Springer: New York, NY, USA, 2009; pp. 77-101.

41. Pretty, J. Social capital and the collective management of resources. Science 2003, 302, 1912-1914.

42. Berkes, F. Evolution of co-management: Role of knowledge generation, bridging organizations and social learning. J. Environ. Manag. 2009, 90, 1692-1702.

43. Westley, F.R.; Tjornbo, O.; Schultz, L.; Olsson, P.; Folke, K.; Crona, B.; Bodin, Ö. A theory of transformative agency in linked social-ecological systems. Ecol. Soc. 2013, 18, Article 27.

44. Moore, M.-L.; Westley, F.R. Surmountable chasms: Networks and social innovation for resilient systems. Ecol. Soc. 2011, 16, Article 5.

45. Olsson, P.; Folke, K.; Galaz, V.; Hahn, T.; Schultz, L. Enhancing the fit through adaptive co-management: Creating and maintaining bridging functions for matching scales in the Kristianstads Vattenrike Biosphere Reserve, Sweden. Ecol. Soc. 2007, 12, Article 28.

46. Olsson, P.; Folke, C.; Hahn, T. Social-ecological transformation for ecosystem management: The development of adaptive co-management of a wetland landscape in southern Sweden. Ecol. Soc.

2004, 9, Article 2. 
47. Borgström, P.; Elmqvist, T.; Angelstam, P.; Alfsen-Norodom, C. Scale mismatches in management of urban landscapes. Ecol. Soc. 2006, 11, Article 16.

48. Olsson, P.; Folke, C.; Hughes, T.P. Navigating the transition to ecosystem-based management of the Great Barrier Reef, Australia. Proc. Natl. Acad. Sci. USA 2008, 105, 9489-9494.

(C) 2015 by the author; licensee MDPI, Basel, Switzerland. This article is an open access article distributed under the terms and conditions of the Creative Commons Attribution license (http://creativecommons.org/licenses/by/4.0/). 